\title{
Measuring the Feeding Behavior of Lactating Dairy Cows in Early to Peak Lactation
}

\author{
T. J. DeVries, ${ }^{\star}$ M. A. G. von Keyserlingk, ${ }^{\star}$ D. M. Weary, ${ }^{\star}$ and K. A. Beauchemin† \\ *Animal Welfare Program, Faculty of Agricultural Sciences, \\ The University of British Columbia, 2357 Main Mall, \\ Vancouver V6T 1Z4, Canada \\ †Agriculture and Agri-Food Canada, P.O. Box 3000, \\ Research Centre, Lethbridge, \\ Alberta T1J 4B1, Canada
}

\begin{abstract}
The objectives of this study were to: 1) objectively define meal criteria (minimum interval between meals) of free-stall housed cows fed via a feed alley, 2) determine which measures of feeding behavior were most repeatable, and 3) describe changes in the feeding behavior from early to peak lactation. An electronic monitoring system was used to record individual cow presence (hits; 6 -s resolution) at the feed alley for 21 lactating cows for three 8-d periods: period 1, $35 \pm 16$ (mean $\pm \mathrm{SD}$ ), period 2 , $57 \pm 16$, and period $3,94 \pm 16$ DIM. A mixture distribution model was used to calculate the meal criterion (27.74 min) by fitting the $\log _{10}$ frequency distribution of the intervals between hits. The within-cow repeatability was highest for feeding activity (hits $\mathrm{d}^{-1}$ ) and intensity (hits per meal $\mathrm{min}$ ), moderate for total daily mealtime ( $\mathrm{min}$ $\mathrm{d}^{-1}$ ) and meal duration (min meal ${ }^{-1}$ ), and lowest for meal frequency (meals $\mathrm{d}^{-1}$ ). From periods 1 to 2, all cows showed increases in total daily mealtime, meal frequency, and meal duration; however, cows with lower meal frequencies and feeding intensity in period 1 showed the greatest increases. Cows with high feeding activity and intensity during period 2 showed proportionally greater increases during period 3 . These results illustrate that some measures of feeding behavior are highly repeatable within cows, but variable between cows and across stages of lactation. Thus, tests of treatment effects on feeding behavior should be within cow and control for days in milk.
\end{abstract}

(Key words: feeding behavior, dairy cow, stage of lactation)

\section{INTRODUCTION}

Promoting feed intake by lactating dairy cattle is critical in terms of improving milk production, health, and

Received April 11, 2003.

Accepted May 13, 2003.

Corresponding author: T. DeVries; e-mail: trevorjd@interchange. ubc.ca. body condition of the animal (Grant and Albright, 1995). Research in this area requires knowledge of both nutrition and behavior (Nielsen, 1999); however, the difficulty in manually collecting behavioral data at the time of feeding has limited the extent of this research (Friggens et al., 1998). The use of time-lapsed video recordings (Vasilatos and Wangsness, 1980; Menzi and Chase, 1994) and recent advances in the development of computerized recording systems have resulted in a renewed interest in obtaining information on feeding behavior (Gibb et al., 1998).

Grant and Albright (2000) reviewed much of this literature and concluded that management factors such as grouping strategy, feeding system design and apparatus, composition and physical characteristics of the feed being consumed, as well as social hierarchy and competition for food and water all influenced the feeding behavior of cattle. However, there has been little work on more basic issues such as the temporal patterning of feeding, and how feeding bouts are divided into meals. This basic work can provide a solid basis for future applied studies by showing what measures of feeding behavior are most repeatable and how alternative measures are correlated.

Animals typically divide their feeding time into a series of meals separated by nonfeeding intervals (Forbes, 1995), and this is also the case with dairy cows (Tolkamp et al., 1998, 2000). However, identifying which intervals are between meals, versus shorter gaps within a meal, can be problematic. Consider the types of intervals that can occur between visits to the feed alley. In some cases, the cow may simply lift her head for a few seconds. In others, she may withdraw from the alley for less than a minute or so when, for example, she is displaced by a dominant cow and must move to another location on the alley or she may leave for several minutes when she visits the water trough elsewhere in the pen. Finally, in cases in which she goes to lie down in a stall she may be away for an extended period of time.

In their pioneering work determining which intervals are between meals and which are within meals, Tolkamp and colleagues (Tolkamp et al., 1998; Tolkamp and Kyri- 
azakis, 1999; Yeates et al., 2001) used the distribution of a large sample of intervals to define objectively the meal criterion (i.e., the minimum interval between visits to consider the next feed alley visit as being part of a new meal). These authors argued that previous approaches to this problem (e.g., Slater and Lester, 1982; Sibly et al., 1990; Langton et al., 1995) had assumed incorrectly that the probability of an animal initiating a meal was independent of the time since the last meal. Tolkamp et al. (1998) showed that this issue could be more appropriately addressed by plotting the frequency distribution of intervals (typically log transformed) and using discontinuities in the distribution to determine objectively which intervals were within meals and which were between meals.

The research by Tolkamp and colleagues (1998, 1999, 2001) was based on the behavior of cows restricted to eating from specific feeding stations and, thus, may not account for all of the competitive interactions that occur during feeding in commercial loose housed systems. One aim of the current study was to replicate this work using free-stall housed cows fed via a feed alley. In addition, no work has examined the within-cow repeatability of various measures of feeding behavior. This is important, as future research will be limited if based on measures that are only weakly repeatable. Thus, a second aim of this study was to use repeated observations of various measures to determine which of these measures are most repeatable. Finally, a third objective of the current study was to describe changes in feeding behavior from early to peak lactation.

\section{MATERIALS AND METHODS}

\section{Experimental Design}

Ten primiparous and 11 multiparous lactating Holstein cows, which had a 305-d milk production of 11,000 \pm 2916 (mean \pm SD) $\mathrm{kg}$, were housed together as a single group and monitored using the GrowSafe feed alley monitoring system (Grow Safe Systems Ltd., Airdrie, AB, Canada) from early to peak lactation. The cows were housed in a free-stall barn located at The University of British Columbia Dairy Education and Research Centre (Agassiz, BC, Canada) and were managed according to the guidelines set by the Canadian Council on Animal Care (1993). Each animal had access to a free stall that was filled with deep-bedded sand. For the entire experiment, the cows were fed a TMR consisting of $20 \%$ corn silage, $20 \%$ grass silage, $7 \%$ alfalfa hay, $3 \%$ grass hay, and $50 \%$ grain concentrate mash on a DM basis. The TMR was formulated according to the NRC (2001) nutrient requirement recommendations for high producing dairy cows. Cows were fed from a feed alley $(0.6 \mathrm{~m}$ of space/cow) with access via a neck rail. Animals were fed daily at approximately 0600 and $1515 \mathrm{~h}$ and were milked at approximately 0530 and $1530 \mathrm{~h}$ daily. Feeding behavior of all cows was recorded for a minimum of $8 d$ for three time periods between early and peak lactation. Data collection during periods 1,2 , and 3 began when cows were at $35 \pm 16$ (mean \pm SD), $57 \pm 16$, and $94 \pm$ 16 DIM, respectively. The experiment was conducted between September 23, 2001, and December 6, 2001.

\section{Feeding Behavior Data Collection}

An electronic feed alley monitoring system (GrowSafe), originally described by Sowell et al. (1998) and modified and validated by Schwartzkopf-Genswein et al. (1999) was used in this study. It was modified further in the present study to allow for data transfer from the reader panel to the computer via radio frequency. Its use with cattle fed via a feed alley also required installation of the antenna mats (each $7.2 \mathrm{~m}$ long and $0.75 \mathrm{~m}$ wide) directly onto the floor of the feed alley adjacent to the tombstone, thereby allowing the feed to be delivered on top of the mats. All experimental animals were fitted with a passive transponder, which was encased in a plastic ear tag (All Flex, Inc., Dallas, TX) and attached to the bottom of the neck collar. When a cow placed her head under the neck rail and over the feed such that the transponder came within $50 \mathrm{~cm}$ of the antenna mat, a signal was immediately transmitted to the reader panel. The reader panel continued to record the presence (a 'hit') of each transponder every $6 \mathrm{~s}$ for as long as the transponder was within the read range of the antenna. The data (transponder number and time stamp) were downloaded continuously via radio frequency to a computer housed approximately $100 \mathrm{~m}$ from the panel. The computer was equipped with GrowSafe feed alley monitoring software version 6.38.

\section{Feeding Behavior Analysis}

The meal criteria were calculated using the $\log _{10}$-frequency distribution of the interval lengths between hits for each individual animal for each time period. The three time periods were chosen to capture possible changes in feeding behavior from early to peak lactation. Although a minimum of $8 \mathrm{~d}$ of feeding behavior data were collected for each period, in the case of periods 1 and 3, extra days (2 and 8, respectively) were collected to provide an increased sample size of intervals to better estimate the meal criterion The scanning interval employed by the GrowSafe system results in a natural periodicity of hit intervals at $6 \mathrm{~s}$ and multiples of 6 . On a $\log _{10}$ scale these were most evident at 6,12 , and $18 \mathrm{~s}$, and this periodicity distorted the frequency distribution in such a way that it could not be modeled statistically. 
Therefore, hit intervals less than $1.3 \log _{10} \mathrm{~s}(\sim 19 \mathrm{~s})$ were removed before analysis. Meal criteria were calculated by fitting a mixture of two normal distributions to the distributions of $\log _{10}$-transformed hit intervals. The software package MIX 3.1.3 (Macdonald and Green, 1988) was used to fit these mixture distributions using the method of exact maximum likelihood. This method used the mixed probability density function:

$$
g(\chi \mid \pi, \mu, \sigma)=\pi_{1} f\left(\chi \mid, \mu_{1}, \sigma_{1}\right)+\ldots+\pi_{k} f\left(\chi \mid, \mu_{k}, \sigma_{k}\right),
$$

where $g$ is a weighted sum of $k$ component densities. In the present study, $k=2$, represented the two distributions of intervals: those within meal and those between meals. When fitting the distribution, the population of intermeal intervals (left-hand distribution) was left truncated due to the removal of the intervals less than $1.3 \log _{10} \mathrm{~s}$. The meal criterion was determined as the point at which the distribution curve of intermeal intervals intersected the distribution curve of the intrameal intervals. Individual meal criteria were calculated for each cow for each time period and a pooled criterion was calculated using the intervals from all cows for all time periods. The calculated meal criteria were used to calculate meal frequency (meals $\mathrm{d}^{-1}$ ), simply by counting the number of intervals that exceeded the criterion and adding one. Meal duration (min meal ${ }^{-1}$ ) was calculated as the time from the first hit until, but not including, a hit interval that exceeded the criterion. Total daily mealtime $\left(\operatorname{min~}^{-1}\right)$ was simply the sum of these meal durations. These measures were calculated using the GrowSafe feed alley monitoring software. In addition to these derived measures based on the meal criterion, we also recorded the number of hits (feeding activity). For example, if a cow were at the feed alley continuously for $6 \mathrm{~h}, 3600\left(21,600 \mathrm{~s} / 6 \mathrm{~s} \mathrm{hit}^{-1}\right)$ hits would be recorded. Feeding intensity was calculated by dividing the number of hits per day by the total daily mealtime.

\section{Statistical Analysis}

The individual animal was considered the observational unit in all analyses. Due to technical difficulty with the GrowSafe equipment, data were not collected for $\mathrm{d} 6$ of period 1 . After an infinite number of iterations, the MIX software was unable to fit the individual interval distribution for two cows in period 3 , resulting in no meal criterion for these animals for this period. The feeding behavior measures collected and calculated for the entire period (e.g., for meal frequency, total daily mealtime, meal duration, feeding activity, and feeding intensity) were averaged to generate period means for each cow. All data were analyzed using the regression procedure of SAS (1985). To determine how the derived measures of behavior (i.e., meal frequency) were affected by the use of different estimates of the meal criterion, measures based on the individual criteria were regressed within cow onto those based on the pooled criterion, testing for slope and intercept effects. Linear regression was also used to determine the within-cow repeatability of the repeated measures of feeding behavior. The data for each of the measures were regressed from period 1 to period 2 and from period 2 to period 3 . To determine whether cows changed their feeding behavior from one period to the next, the regression estimates of slope and intercept for the relationships of the individual behavioral measures for periods 1 and 2 and for periods 2 and 3 were tested. For all regression analyses, the intercept was tested for difference from zero, to determine whether cows changed on average, and the slope was tested for difference from one, to determine the extent of the change relative to the initial value.

\section{RESULTS}

\section{Meal Criteria}

Meal criteria were calculated separately for each cow for each time period. It varied among cows ranging from $8.4 \mathrm{~min}$ to $52.7 \mathrm{~min}$; moreover, meal criteria varied among periods ranging from $30.8 \pm 8.9$ (mean \pm SD) $\mathrm{min}$ in period 1 to $26.4 \pm 9.4$ (mean $\pm \mathrm{SD}$ ) $\mathrm{min}$ in period 3 .

The use of the pooled (27.74 $\mathrm{min}$ ) versus the individual meal criteria resulted in very similar estimates of meal frequency and total daily mealtime. The relationships between pooled and individual estimates for period 1 are illustrated in Figure 1. The line equations and coefficients of determination were also calculated for periods 2 and 3 for meal duration $\left(y=1.09 x-34.89, R^{2}=0.95\right.$; and $y=0.94 \mathrm{x}+23.66, \mathrm{R}^{2}=0.86$, respectively) and for meal frequency $\left(\mathrm{y}=0.75 \mathrm{x}+2.02, \mathrm{R}^{2}=0.39\right.$; and $\mathrm{y}=$ $0.96 \mathrm{x}+0.31, \mathrm{R}^{2}=0.77$, respectively). In every case, the coefficient was significant $(P<0.01)$. In addition, the intercept did not differ from zero, and the slope did not differ from one $(P>0.1)$. Furthermore, all analyses reported below were completed using both an individual criterion and a pooled criterion, and the results were similar from both approaches. We therefore used the pooled meal criterion (Figure 2) in all subsequent analyses. Using this criterion, we found an average meal frequency of $7.3 \pm 1.5$ (mean $\pm \mathrm{SD}$ ) meals $\mathrm{d}^{-1}$, meal duration of $47.1 \pm 13.0 \mathrm{~min} \mathrm{meal}^{-1}$, and total daily mealtime of $332.3 \pm 69.2 \mathrm{~min} \mathrm{~d}^{-1}$.

\section{Repeatability of Feeding Behavior Measures}

Linear regression was used to determine the withincow repeatability of the different measures of feeding behavior. For each variable, and for comparisons of both 


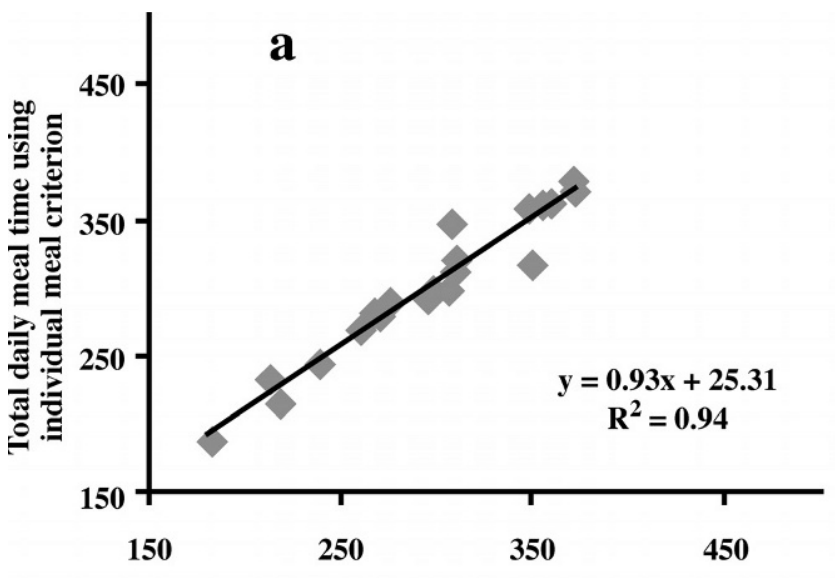

Total daily meal time using a pooled meat criterion

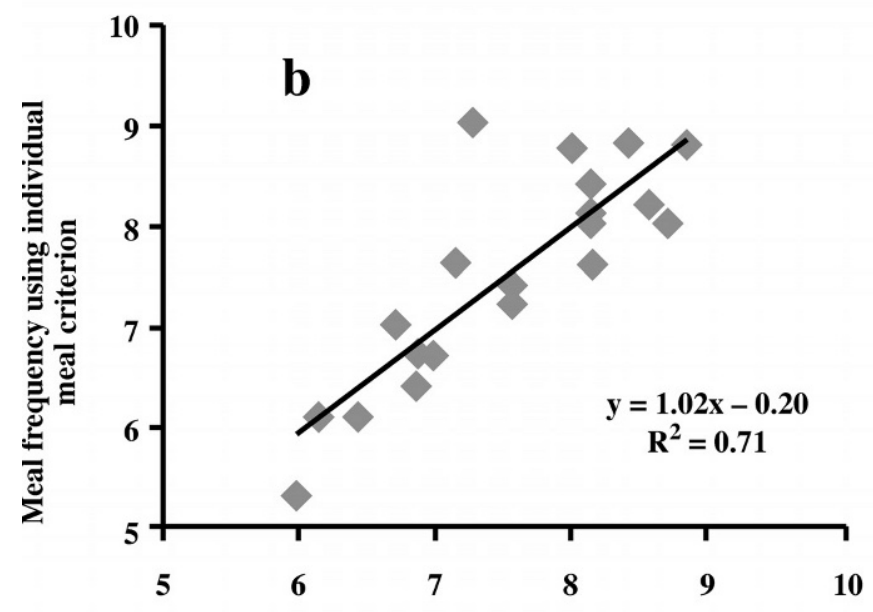

Meal frequency using a pooled meal criterion

Figure 1. The relationship of (a) total daily mealtime $\left(\min \mathrm{d}^{-1}\right)$ and (b) meal frequency (meals $\mathrm{d}^{-1}$ ) calculated with a pooled meal criterion (27.74 min) and with individual meal criterion. Meal frequency and total daily mealtime were calculated for 21 cows averaged for $8 \mathrm{~d}$ starting at an average 35 DIM.

period 1 to period 2 and period 2 to period 3 , regression coefficients of determination were significant $(P<0.05)$, but the extent of repeatability varied considerably depending on the measure of feeding behavior (Table 1). The within-cow repeatability was highest for feeding activity and feeding intensity. For example, the high degree of consistency in feeding activity is shown in Figure 3. Other measures, such as total daily mealtime (Figure 4) showed only moderate repeatability across time periods, and repeated measures of meal frequency were only marginally related.

\section{Changes in Feeding Behavior from Early to Peak Lactation}

Cows changed aspects of their feeding behavior between periods 1 and 2 (Table 2), and again between

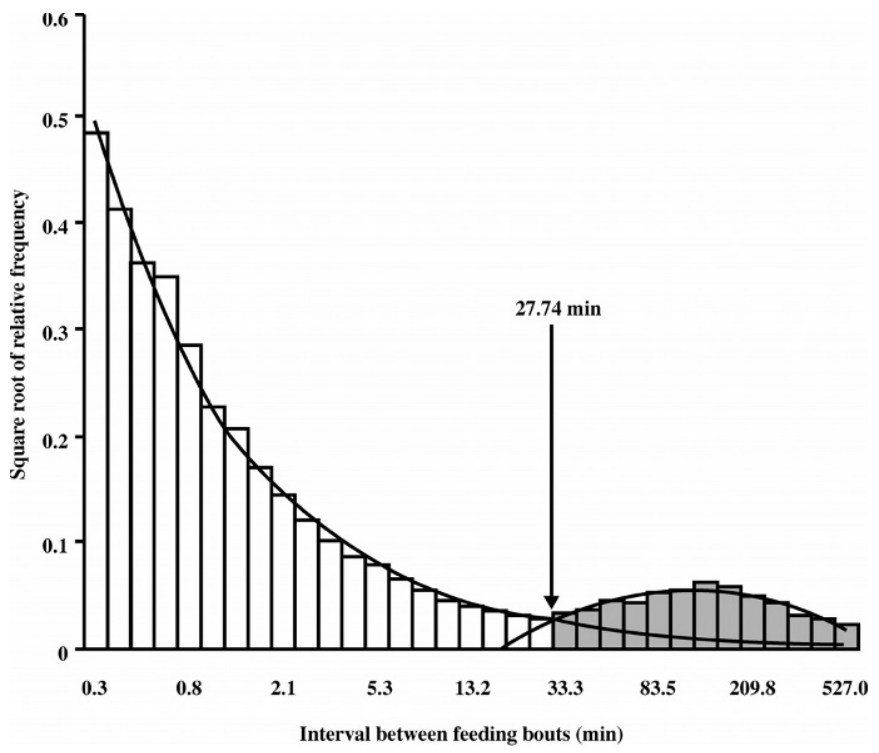

Figure 2. Square-root transformed relative frequency distribution of the intervals $(n=180,676)$ between the electronic feed alley monitoring system data points fitted with a mixed distribution model. Data presented are summarized for 21 cows for the data collected for the three time periods: $10 \mathrm{~d}$ starting at average 35 DIM, $8 \mathrm{~d}$ starting at average 57 DIM, and $16 \mathrm{~d}$ starting at average 94 DIM. Square root transformation is used here to better illustrate the two distributions and was not used in the mixture analysis of the distributions.

periods 2 and 3 (Table 3). Regressions between the first two periods showed intercepts significantly higher than zero for total daily mealtime, meal frequency, and meal duration, indicating general increases in these behaviors across cows. Additionally, cows with lower meal frequencies and feeding intensities during period 1 showed greater increases in period 2, compared with those cows with higher meal frequencies and feeding intensities in period 1 , as indicated by the slopes for these line equations being significantly less than one.

Table 1. Coefficients of determination for the relationship between time periods for different measures of feeding behavior. All relationships are significant at $P<0.05$.

\begin{tabular}{|c|c|c|}
\hline Measure & $\begin{array}{l}\text { Period } 1^{1} \\
\text { vs. period } 2^{2}\end{array}$ & $\begin{array}{l}\text { Period } 2 \\
\text { vs. period } 3^{3}\end{array}$ \\
\hline Feeding activity ${ }^{4}$ & 0.91 & 0.90 \\
\hline Feeding intensity ${ }^{5}$ & 0.85 & 0.91 \\
\hline 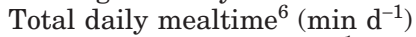 & 0.72 & 0.75 \\
\hline Meal duration (min meal $^{-1}$ ) & 0.55 & 0.50 \\
\hline Meal frequency (meals $\mathrm{d}^{-1}$ ) & 0.34 & 0.22 \\
\hline
\end{tabular}

${ }^{1,2,3}$ Data for each variable were averaged for $8 \mathrm{~d}$ starting at 35,57 , and 94 DIM, respectively, for 21 cows.

${ }^{4}$ The total number of data points that the feed alley monitoring system recorded per day.

${ }^{5}$ The number of hits per day divided by the total daily mealtime.

${ }^{6}$ Sum total length of time (min) included in the meals per day. 


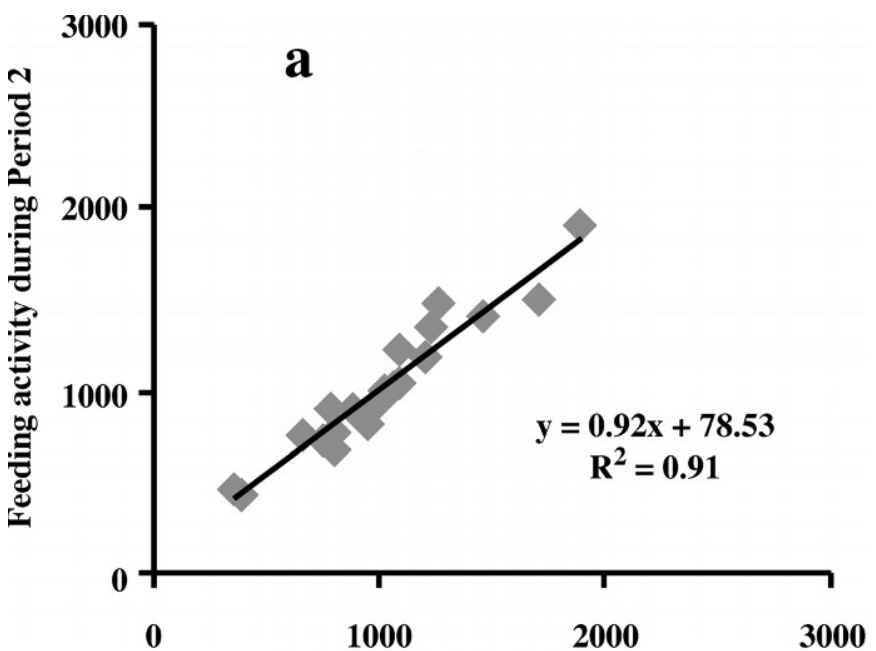

Feeding activity during period 1

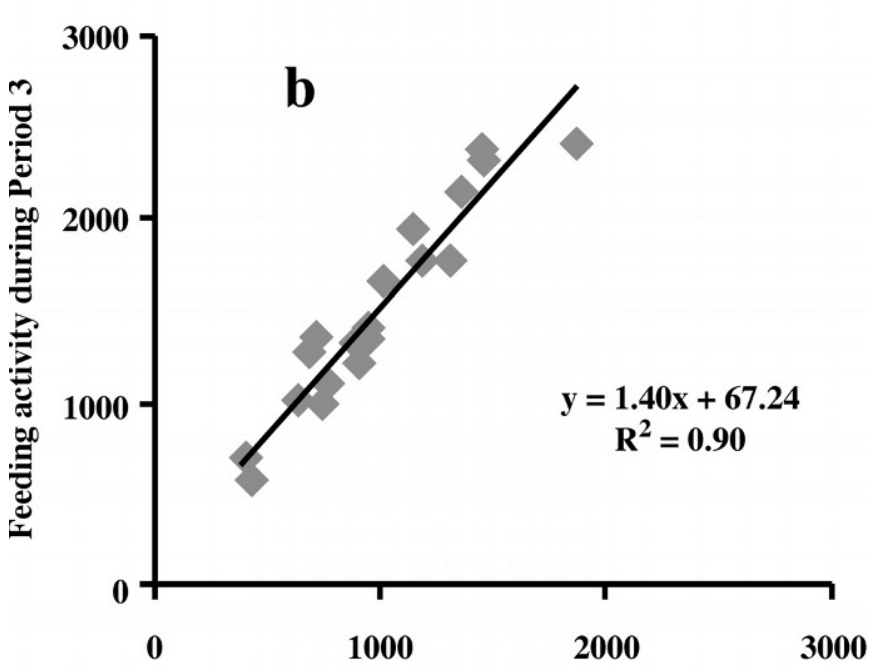

Feeding activity during period 2

Figure 3. The relationship between the average feeding activity (hits $\mathrm{d}^{-1}$ ) of 21 cows for (a) period 1 and 2 and (b) period 2 and 3. Periods 1, 2, and 3 represent 8 -d periods starting at an average of 35,57 , and 94 DIM, respectively.

Cows showed different changes in feeding behavior across periods 2 and 3 . In particular, we found that cows with high feeding activity (hits $\mathrm{d}^{-1}$ ) and feeding intensity (hits per meal min) in period 2 showed proportionally greater increases, as indicated by slopes significantly higher than one for these measures. In contrast, for total daily mealtime and meal frequency, intercepts tended to be above zero and slopes less than one. This was attributed to cows with high values during period 2 showing reduced mealtime and frequencies during period 3 , and cows with low values during period 2 showing increases in period 3.

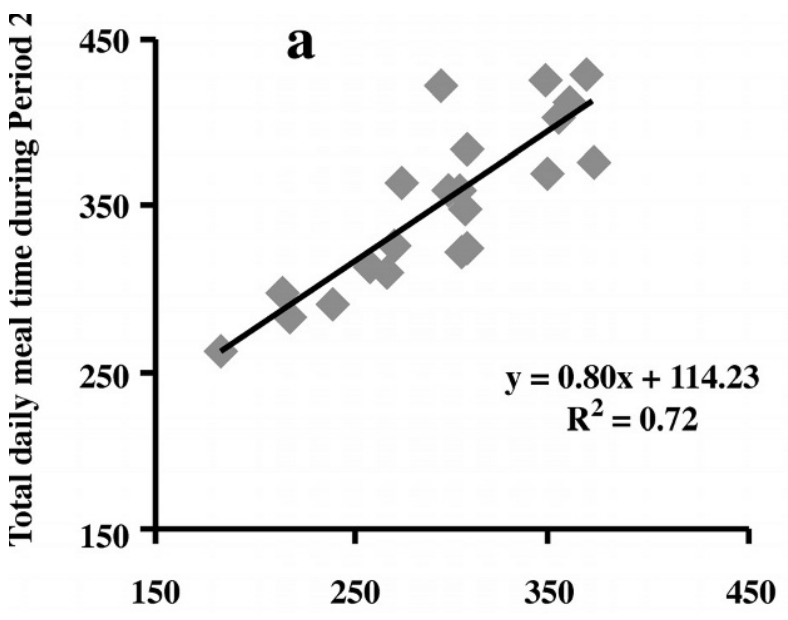

Total daily meal time during period 1

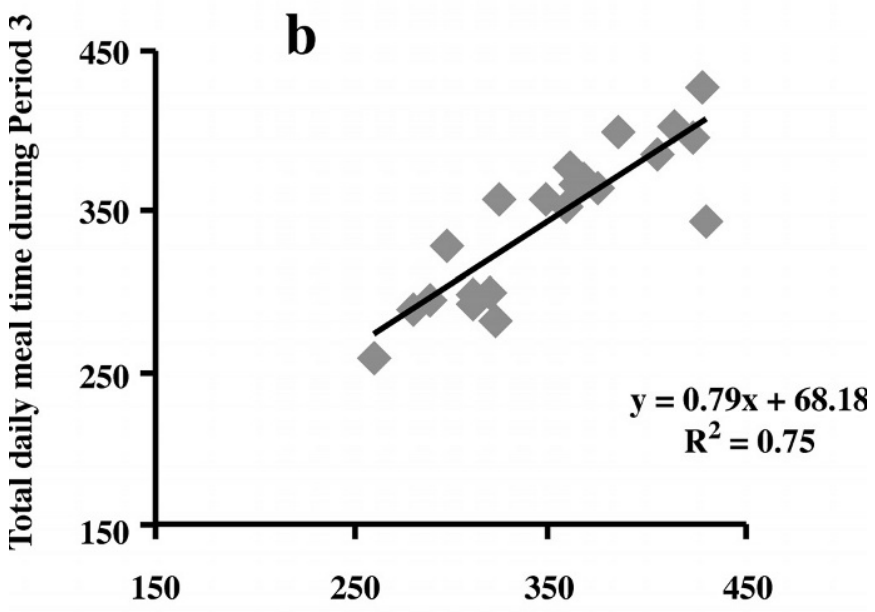

Total daily meal time during period 2

Figure 4. The relationship between the average total daily mealtime (min $\mathrm{d}^{-1}$ ) of 21 cows for (a) periods 1 and 2 and (b) periods 2 and 3 . Periods 1,2 , and 3 represent 8 -d periods starting at an average of 35,57 , and 94 DIM, respectively.

\section{DISCUSSION}

\section{Meal Criteria}

The literature has lacked a cohesive definition of meal criterion (Grant and Albright, 1995). For example, using a subjective assessment of meals and visual observations, Sowell et al. (1999) defined the meal criterion as 5 min for beef feedlot cattle. Gibb et al. (1998) defined meal criterion as 20 min for beef feedlot cattle, but did not specifically state how this value was determined. In the current study, the use of the $\log _{10}$-transformed frequency distributions shows a first peak corresponding to intervals within meals and the second peak representing the intervals between meals. This distribution thus 
Table 2. Intercepts and slopes of line equations from the regression of feeding behavior measures in period $1^{1}$ versus period $2^{2} . P$-values are from tests of the hypotheses that the intercept $=0$ and slope $=1$.

\begin{tabular}{lclll}
\hline Measure & Intercept $\pm \mathrm{SE}$ & $P$ & Slope $\pm \mathrm{SE}$ & $P$ \\
\hline Feeding activity $^{3}$ & $78.54 \pm 69.73$ & 0.27 & $0.92 \pm 0.06$ & 0.22 \\
Feeding intensity $^{4}$ & $0.34 \pm 0.25$ & 0.20 & $0.73 \pm 0.07$ & 0.001 \\
Total daily mealtime $^{5}\left(\mathrm{~min}^{-1}\right)$ & $114.23 \pm 34.27$ & 0.004 & $0.80 \pm 0.11$ & 0.10 \\
${\text { Meal duration }\left(\mathrm{min} \mathrm{meal}^{-1}\right)}^{\text {Meal frequency }\left(\mathrm{meals} \mathrm{d}^{-1}\right)}$ & $19.86 \pm 6.08$ & 0.004 & $0.71 \pm 0.15$ & 0.07 \\
\hline
\end{tabular}

${ }^{1,2}$ Data for each variable were averaged for $8 \mathrm{~d}$ starting at 35 and 57 DIM, respectively, for 21 cows.

${ }^{3}$ The total number of data points that the feed alley monitoring system recorded per day.

${ }^{4}$ The number of hits per day divided by the total daily mealtime.

${ }^{5}$ Sum total length of time ( $\left.\mathrm{min}\right)$ included in the meals per day.

provides an objective and biologically relevant basis for identifying meal criterion; namely, the interval at which the two distributions intersect (Tolkamp et al., 1998). This meal criterion, calculated on an individual animal basis or on a group basis, is then used to determine the derived measures of feeding behavior. The present results showed that although individual cows differed to some degree in their meal criterion, using a pooled criterion (27.74 min) across cows and periods had little effect on the between time period analysis of the feeding behavior measures. Thus, although using a pooled criterion will result in some loss of detail, for some studies at least, this pooled estimate will be adequate. However, in some cases for which there is considerable variation in criteria (e.g., between cows or time periods), or when there are specific predictions concerning the treatment response of the criterion based measures it would be recommended to used individual criteria.

Tolkamp et al. (1998), Tolkamp and Kyriazakis (1999), and Yeates et al. (2001), using a dataset collected from animals trained to feed from predetermined feeding stations, also reported a bimodal frequency distribution of log-transformed intervals. These authors calculated meal criteria ranging from 26.4 to $63.7 \mathrm{~min}$, which was similar to the 8.4 to 52.5 min range found in the current study.

Tolkamp et al. (2000) reported that lactating cows from early to midlactation had an average meal criterion of $44.7 \mathrm{~min}$, consumed 6.1 meals $^{-1}$, and had a meal duration of 36.9 min meal ${ }^{-1}$ resulting in a total daily mealtime of $225.1 \mathrm{~min} \mathrm{~d}^{-1}$. These researchers used the same method described in the current study for estimating meal criterion, and the cows they used were similar in production levels and DMI to the cows used in our study. The longer meal criterion used by Tolkamp et al. (2000) translated into a lower meal frequency but did not increase the meal duration or total daily mealtime to the same levels as in the present study. This difference may indicate that the cows in our study had more nonfeeding within meal intervals, perhaps due to increased disruption by other cows in our system compared with the electronic feeding gates and preassigned feeding stations used by Tolkamp et al. (2000).

The effect of reduced social interactions at the feeder may also explain differences between values obtained in our study and those from studies in which cows were kept in tie stalls. Vasilatos and Wangsness (1980) found that early to peak lactation cows housed in a tie-stall

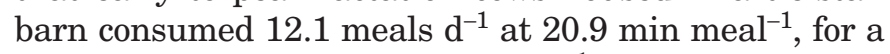
total daily mealtime of $253 \mathrm{~min} \mathrm{~d}^{-1}$. These values are considerably different from those obtained in all three time periods in the present study. In another study, Dado and Allen (1995) found that early lactation cows housed in tie stalls, with similar milk production and diet to the cows used in the present study, consumed 11.9 meals $\mathrm{d}^{-1}$ at $25.9 \mathrm{~min} \mathrm{meal}^{-1}$, for a total daily mealtime of

Table 3. Intercepts and slopes of line equations from the regression of feeding behavior measures in period $2^{1}$ versus period $3^{2}$. P-values are from tests of the hypotheses that the intercept $=0$ and slope $=1$.

\begin{tabular}{|c|c|c|c|c|}
\hline Measure & Intercept $\pm \mathrm{SE}$ & $P$ & Slope \pm SE & $P$ \\
\hline Feeding activity ${ }^{3}$ & $67.24 \pm 112 . .38$ & 0.56 & $1.40 \pm 0.11$ & 0.001 \\
\hline Feeding intensity ${ }^{4}$ & $-0.50 \pm 0.35$ & 0.17 & $1.67 \pm 0.12$ & 0.001 \\
\hline Total daily mealtime ${ }^{5}\left(\operatorname{min~}^{-1}\right)$ & $68.18 \pm 37.17$ & 0.08 & $0.79 \pm 0.11$ & 0.06 \\
\hline Meal duration (min meal $\left.{ }^{-1}\right)$ & $8.07 \pm 9.96$ & 0.43 & $0.89 \pm 0.20$ & 0.58 \\
\hline Meal frequency (meals d ${ }^{-1}$ ) & $3.04 \pm 1.70$ & 0.09 & $0.53 \pm 0.23$ & 0.05 \\
\hline
\end{tabular}

${ }^{1,2}$ Data for each variable were averaged for $8 \mathrm{~d}$ starting at 57 and 94 DIM, respectively, for 21 cows.

${ }^{3}$ The total number of data points that the feed alley monitoring system recorded per day.

${ }^{4}$ The number of hits per day divided by the total daily mealtime.

${ }^{5}$ Sum total length of time ( $\mathrm{min}$ ) included in the meals per day. 
$294 \mathrm{~min}^{-1}$. Even though the value for total daily mealtime is close to that found in the present study, the values for meal frequency and duration are quite different. It can be theorized that with less social disruption in tie stalls, we would expect fewer within-meal disruptions, translating into more frequent, shorter meals, as seen in both of these previous studies. Additionally, the meal criteria used in these studies were not defined in the same way as the present study, which may account for some of the variability between the results.

\section{Repeatability of Feeding Behavior Measures}

Measurements typically used to describe feeding behavior include meal frequency and duration (Senn et al., 1995; Nielsen, 1999). Researchers (Vasilatos and Wangsness, 1980; Dado and Allen, 1994; Nielsen, 1999) have tried to examine the relationships between feeding behavior variables, but, to our knowledge, no previous work has attempted to measure the repeatability of any measure of feeding behavior in dairy cattle. In the current study, we used a sensitive within-cow test and found that all measures were significantly related between time periods. We also found that the nonderived measures (e.g., hit frequency) showed far superior repeatability than the derived measures (e.g., meal frequency). Thus, even though cows organize their feeding bouts into meals, measures based on meals (e.g., meal frequency and duration) tend to be variable, and will likely prove to be relatively insensitive as measures to assess treatment differences. Because the highest within-cow repeatability was seen in the feeding activity and intensity measures, we recommend that future research use these measures in assessing treatment effects on feeding behavior except when researchers have specific predictions concerning the treatment response of the criterion based measures.

\section{Changes in Feeding Behavior from Early to Peak Lactation}

There was substantial between-cow variation for all measures of feeding behavior for all three time periods. Examples of this can be seen in Figures 3 and 4, for the measures of feeding activity and total daily mealtime. This high between-cow variability indicates that relatively little can be learned from comparing the absolute values of these measures in different studies, or even the values from different cows within a study. Thus, we used within-cow regression analysis to compare time periods.

Previous research on feeding behavior of dairy cows has typically not considered the effects of differences in stage of lactation. In this present experiment, we mea- sured the feeding behavior of the same group of cows at three different time periods from early to peak lactation. The relationships between the individual behavioral measures for periods 1 and 2 (Table 2) and for periods 2 and 3 (Table 3) indicated several changes in dairy cattle feeding behavior from early to peak lactation. The total daily mealtime was increased from period 1 to period 2. This was not surprising since DMI has been shown to be continually increasing from the beginning of lactation to approximately 9 wk into lactation (Kertz et al., 1991). The results from the comparison between periods 2 and 3 indicated there was no overall increase or decrease in total daily mealtime. Rather, it appears that the animals stabilized their feeding behavior between periods 2 and 3 . In terms of meal frequency, there was a proportional increase in the number of meals per day; the cows that had fewer meals per day during period 1 had the greatest increase. Again, meal frequency was relatively stable between periods 2 and 3 . The increased total daily mealtime and meal frequency from periods 1 to 2 also translated into an increase in meal duration, and this measure also remained stable between periods 2 and 3. Friggens et al. (1998) studied the effects of stage of lactation on the short-term feeding behavior of dairy cows. These authors found no significant effect of stage of lactation for any of the behavior measures (visits to feed bin, duration of the visit, and food intake per visit). They also reported that even though DMI dropped in the later stages of lactation, there was no associated change in feeding behavior. The difference between these findings and those from the current study may have been due to different measures of feeding behavior and no definition of meal criterion (Friggens et al., 1998).

In addition to the changes over time, in the behavioral measures calculated with a meal criterion, changes were also detected in the measures derived from the hits produced by the GrowSafe system. The feeding activity of the cows remained unchanged from periods 1 to 2 ; however, from period 2 to 3 there was a proportional increase (40\% per cow) in feeding activity. The change in total daily mealtime from periods 1 to 2 associated with no change in feeding activity, resulted in cows proportionally reducing their feeding intensity during period 2 . This indicates that even though they were spending more time in activities associated with eating, they were not spending any more time consuming feed at the feed alley. The increase in feeding activity from period 2 to period 3 associated with no change in total daily mealtime translated into a proportional increase $(67 \%)$ in feeding intensity in period 3 . These increases in feeding activity and intensity indicate that during this peak production period, cows were spending more of their mealtime actually at the feed alley and reducing the intrameal intervals away from the alley. 


\section{CONCLUSIONS}

The use of the $\log _{10}$-normal model described by Tolkamp et al. (1998) allows for the identification of a biologically relevant meal criterion for the feeding behavior of lactating dairy cows in early to peak lactation with unrestricted access to the feed alley. This criterion provides an objective basis for calculations of meal frequency, meal duration, and total daily mealtime, and we recommend that this technique be employed in future research on feeding behavior. Also, the measures of feeding activity and intensity obtained using the electronic feed alley monitoring system can provide more repeatable and potentially more sensitive measures of responses to treatments that affect feeding behavior. The large amount of between-cow variability for all measures necessitates the use of within-cow tests when testing for changes in feeding behavior. In addition to this, studies of treatment effects on feeding behavior should control for DIM.

\section{ACKNOWLEDGMENTS}

We thank the staff and students at The University of British Columbia's Dairy Education and Research Centre and the University's Animal Welfare Program. We also thank Peter Macdonald from McMaster University for his help with the mixture distribution analysis. Trevor DeVries was supported by a Natural Sciences and Engineering Research Council of Canada Postgraduate Scholarship. The project was funded by the Natural Sciences and Engineering Research Council of Canada, through the Industrial Research Chair in Animal Welfare, and by contributions from the Dairy Farmers of Canada, the Beef Cattle Industry Development Fund, the BC Dairy Foundation, the BC SPCA, members of the BC Veterinary Medical Association, and many other donors listed on our website at http://www.agsci.ubc.ca/animalwelfare.

\section{REFERENCES}

Canadian Council on Animal Care. 1993. Guide to the Care and Use of Experimental Animals. Vol. 1. E. D. Olfert, B. M. Cross, and A. A. McWilliam, eds. CCAC, Ottawa, ON, Canada.

Dado, R. G., and M. S. Allen. 1994. Variation in and relationships among feeding, chewing, and drinking variables for lactating dairy cows. J. Dairy Sci. 77:132-144.

Dado, R. G., and M. S. Allen. 1995. Intake limitations, feeding behavior, and rumen function of cows challenged with rumen fill from dietary fiber or inert bulk. J. Dairy Sci. 78:118-133.

Forbes, J. M. 1995. Voluntary Food Intake and Diet Selection in Farm Animals. CAB Int., Wallingford, United Kingdom.
Friggens, N. C., B. L. Nielsen, I. Kyriazakis, B. J. Tolkamp, and G. C. Emmans. 1998. Effects of food composition and stage of lactation on the short-term feeding behavior of dairy cows. J. Dairy Sci. 81:3268-3277.

Gibb, D. J., T. A. McAllister, C. Huisma, and R. D. Wiedmeirer. 1998. Bunk attendance of feedlot cattle monitored with radio frequency technology. Can. J. Anim. Sci. 78:707-710.

Grant, R. J., and J. L. Albright. 1995. Feeding behavior and management factors during the transition period in dairy cattle. J. Anim. Sci. 73:2791-2803.

Grant, R. J., and J. L. Albright. 2000. Feeding Behaviour. Pages 365382 in Farm Animal Metabolism and Nutrition. J. P. F. D’Mello, ed. CABI Publishing, Wallingford, Oxon, UK.

Kertz, A. F., L. F. Reutzel, and G. M. Thomson. 1991. Dry matter intake from parturition to midlactation. J. Dairy Sci. 74:22902295.

Langton, S. D., D. Collett, and R. M. Sibly. 1995. Splitting behaviour into bouts: A maximum likelihood approach. Behaviour 132:781-799.

MacDonald, P. D. M., and P. E. J. Green. 1988. User's Guide to Program MIX: An interactive program for fitting mixtures of distributions. Release 2.3, January 1988. Ichthus Data Systems, Hamilton, Ontario, Canada.

Menzi, W., Jr., and L. E. Chase. 1994. Feeding behavior of cows housed in free stall barns. Pages 829-833 in Dairy Systems for the 21st Century. American Society of Agricultural Engineers, St. Joseph, MI.

National Research Council. 2001. Nutrient Requirements of Dairy Cattle. 7th rev. ed. National Academy Press, Washington, DC.

Nielsen, B. L. 1999. On the interpretation of feeding behaviour measures and the use of feeding rate as an indicator of social constraint. Appl. Anim. Behav. 63:79-91.

SAS User's Guide: Statistics, Version 5 Edition. 1985. SAS Inst., Inc., Cary, NC.

Schwartzkopf-Genswein, K. S., C. Huisma, and T. A. McAllister. 1999. Validation of a radio frequency identification system for monitoring the feeding patters of feedlot cattle. Livest. Prod. Sci. 60:27-31.

Senn, M., B. Durst, A. Kaufmann, and W. Langhans. 1995. Feeding patterns of lactating cows of three different breeds fed hay, corn silage, and grass silage. Physiol. Behav. 58:229-236.

Sibly, R. M., H. M. R Nott, and D. J. Fletcher. 1990. Splitting behaviour into bouts. Anim. Behav. 39:63-69.

Slater, P. J. B., and N. P. Lester. 1982. Minimising errors in splitting behaviour into bouts. Behaviour 79:153-161.

Sowell, B. F., J. P. G. Bowman, M. E. Branine, and M. E. Hubbert. 1998. Radio frequency technology to measure feeding behavior and health of feedlot steers. Appl. Anim. Behav. 59:277-284.

Sowell, B. F., M. E. Branine, J. G. P. Bowman, M. E Hubbert, H. E. Sherwood, and W. Quimby. 1999. Feeding and watering behavior of healthy and morbid steers in a commercial feedlot. J. Anim. Sci. 77:1105-1112.

Tolkamp, B. J., D. J. Allcroft, E. J. Austin, B. L. Nielsen, and I. Kyriazakis. 1998. Satiety splits feeding behaviour into bouts. J. Theor. Biol. 194:235-250.

Tolkamp, B. J., and I. Kyriazakis. 1999. To split behaviour into bouts, log-transform the intervals. Anim. Behav. 57:807-817.

Tolkamp, B. J., D. P. N. Schweitzer, and I. Kyriazakis. 2000. The biologically relevant unit for the analysis of short-term feeding behavior of dairy cows. J. Dairy Sci. 83:2057-2068.

Vasilatos, R., and P. J. Wangsness. 1980. Feeding behavior of lactating dairy cows as measured by time-lapse photography. J. Dairy Sci. 63:412-416.

Yeates, M. P., B. J. Tolkamp, D. J. Allcroft, and I. Kyriazakis. 2001. The use of mixed distribution models to determine bout criteria for analysis of animal behaviour. J. Theor. Biol. 213:413-425. 